\title{
Adoption rate forecasts and rollout strategies
}

\author{
Kjell Stordahl • Nils Kristian Elnegaard
}

Accepted: 24 April 2008 / Published online: 31 May 2008

(C) The Author(s) 2008

\begin{abstract}
Long-term broadband penetration forecasts for Western Europe are presented. The broadband penetration forecasts are adjusted according to the broadband coverage. The adjusted forecasts are defined as adoption rate forecasts. These forecasts are used as input to the techno-economic calculations to examine broadband roll out in the different access area types. The paper documents the profitability of broadband rollouts in sparsely populated areas and estimates the limits for having monopoly areas as a function of given characteristics. The identified monopoly areas will of course contribute to higher broadband coverage because the profitability in these small areas will be better than earlier expected because of none competition.
\end{abstract}

Keywords Residual broadband market - Adoption rate forecasts • DSL rollout strategies

\section{Introduction}

In 2004 the Norwegian government gave the following statement regarding broadband:

The government looks at deployment of the broadband network as establishment of a national infrastructure, which during the coming years will be as important for evolution of the modern Norway as the telephone network, power line network, railway network, roads, water and sewage network earlier have been for the Norwegian Society.

K. Stordahl $(\bowtie) \cdot$ N. K. Elnegaard

Telenor Nordic, Snarøyvn 30, 1331 Fornebu, Norway

e-mail: kjell.stordahl@telenor.com 
In 2005 the newly elected Norwegian government announced that they wanted to roll out broadband to entire country within the end of 2007. The Norwegian Ministry of Government Administration and Reform has calculated the cost to cover the last $5 \%$ of the Norwegian rural areas to about 120 million Euro.

The Norwegian government had so far utilised the free market dynamics and handed over the broadband deployment to the operators. To speed up rollout of the very last part of the infrastructure, which so far is not commercially profitable, the government has decided to support with the financing.

This paper does not analyse Norwegian business cases. The paper analyses the residual markets in Western Europe.

\section{Broadband adoption rate}

Usually the broadband demand in a given country is characterized by the broadband penetration. To be able to identify the potential broadband demand, defined as broadband adoption rate, we need to know the broadband penetration and the coverage. Suppose that the rollout at time $t$ gives the broadband coverage, $C_{t}$, and that the broadband penetration at that time is $P_{t}$. The broadband adoption rate (or take rate), $A_{t}$, is the ratio between demand and coverage in an area.

$$
A_{t}=P_{t} / C_{t}
$$

The same relation is valid not only for the total broadband penetration, but also for the penetration of different broadband technologies and for disaggregated areas.

Suppose that the broadband coverage in a country is $80 \%$ and the broadband penetration $25 \%$. When broadband is deployed and offered in a new area, the real broadband demand (adoption rate) in this area is $31 \%$, not $25 \%$.

Long-term adoption rate forecasts are important for evaluation of broadband rollout strategies. The long-term adoption rate forecasts are used to make rollout strategies for high capacity broadband ADSL2+/VDSL2 and for broadband rollout in sparsely populated areas.

\section{Broadband rollout strategies in dense urban areas}

Stordahl [1] describes the long-term broadband penetration forecasts. Sections 3 and 4 in [2] describes the ADSL2+/VDSL rollout strategy by starting with the largest exchanges because the coverage is high and the investment per customer is less than in other areas.

The differentiated adoption rate forecasts shown in Fig. 1 in [1], are the key to the rollout strategies. The adoption rate forecasts is shown:

- when an operator enters the area and is alone

- when two operators enters the area at the same time 


\section{Adoption rate as a function of delayed introduction}

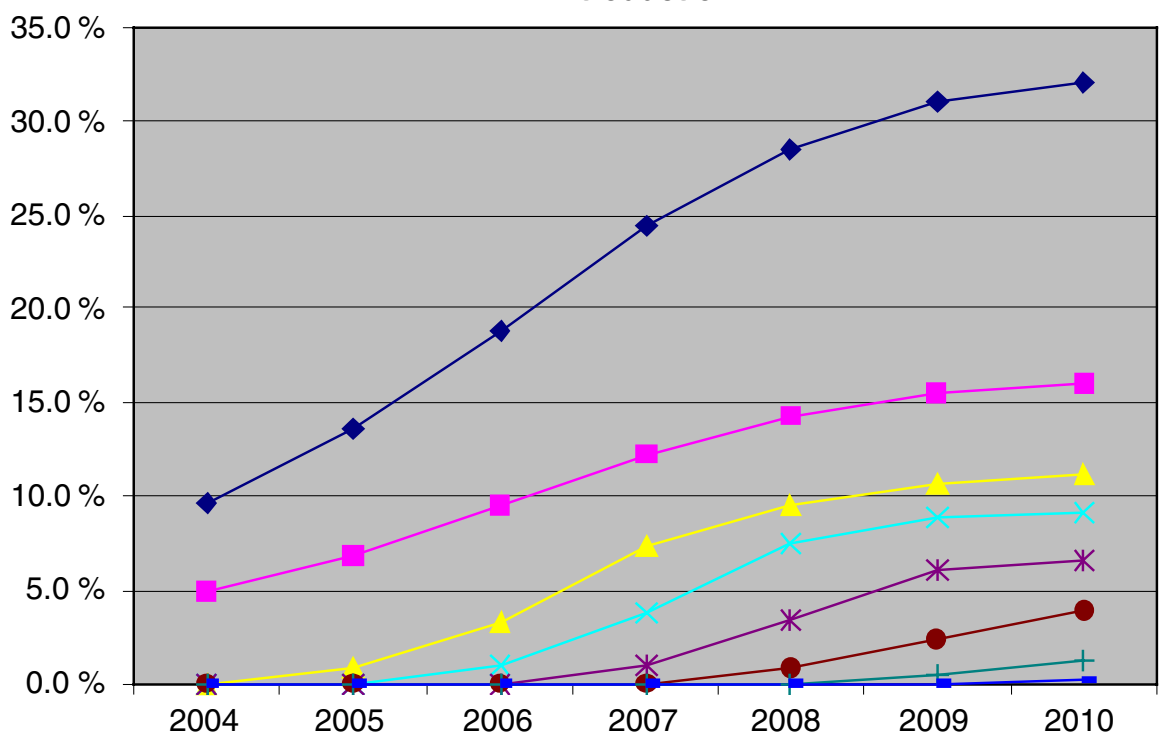

$\longrightarrow$ Alone
$\rightarrow-0$ Year delay $\rightarrow-2$ year delay $\rightarrow-3$ year delay $\longrightarrow 5$ year delay delay
-6

Fig. 1 ADSL2+/VDSL adoption rate forecasts as a function of delayed introduction

- when one operator enters the area one year delayed

- when one operator enters the area two years delayed

- etc

The model for the differentiated adoption rate forecasts assumes that the first operator takes the initial market, while a second operator entering next year takes $20 \%$ of the growth. The second operator takes $35 \%$ of the market growth the second year, and $50 \%$ the next years. Figure 1 shows the adoption rate forecasts for ADSL2+/VDSL based on these assumptions.

The business case is based on rollout of ADSL2+/VDSL in a large country. The high capacity broadband market is divided in five market segments according to the sizes of the exchanges. It is assumed some differentiation in the adoption rate in the different market segments: The larger exchange areas, the higher demand.

The business case is based on competition between two main operators rolling out ADSL2+/VDSL with limited resources each year. Table 7.1-7.6 in [2] show the rollout each year as a percentage of the whole market. The main point is of course to start the rollout in large exchange areas. When the most attractive areas are occupied, the operator continues with the second best and at a given point, the operator enter the most attractive exchange areas 
as the second operator instead of entering small exchange areas. The longterm adoption rate forecasts are an extremely important factor for choosing the most optimal rollout strategy.

The results from scenarios 1-6 give some guidelines for the rollout strategies. Figure 9.1 and 9.2 in [2] show that two years delayed rollout for the incumbent gives very poor results, while an aggressive rollout of the incumbent gives high NPV.

It is interesting to see that the largest operator in Europe seems to follow the strategy based on adoption rate forecasts presented in this paper. Deutsche Telecom announced 14. November 2005 that they have decided to spend 3 Billion Euro to roll out a VDSL FTTN in Germany [3].

\section{Broadband rollout strategies in the residual market}

During the last five years West European countries have rolled out broadband extensively. DSL technology is the dominating technology followed by HFC. Most of the countries in Western Europe still have a residual market, which so far is not covered by broadband. The size of the residual market in Western Europe varies mainly between $5 \%$ and $10 \%$ of the total market size. For countries outside Western Europe the residual market is on average much higher. Exceptions are: South Korea, Taiwan, USA, Canada and some others.

The strategy for the broadband rollout has been to cover the most densely populated areas as the first step. DSLAMs have been installed in large exchange areas, and cable networks with many subscribers have been upgraded to HFC. Also wireless systems have been used for the coverage. By entering the most densely populated areas, the operators secured high market shares and also low investments per customer. High net present value and relatively short pay back period have generated the broadband rollouts so far.

At present, only more sparsely populated areas have no broadband coverage in Western Europe. This paper shows that important factors like increased broadband demand, lower production price of broadband equipment and relatively higher market shares for operators who are entering smaller areas give reasonable good business cases also in these areas.

The paper pays specific attention to DSL technology and rollout strategies in the residual broadband market. DSL is the dominating technology in rural areas. The residual market consists of parts of the access network with too long copper lines and areas with too few potential subscribers, where broadband so far has not been rolled out. The analysis presented in this paper shows how DSL can be deployed in smaller areas to increase the broadband coverage.

\subsection{Residual broadband market}

The residual broadband market is defined as the part of the market, which is not covered by broadband accesses. $100 \%$ minus the broadband percentage coverage is a measure for the residual broadband market. The broadband 
coverage is a function of rollout of different broadband technologies like DSL, HFC (cable modem), FWA, FTTB/FTTH etc. The definition of broadband is not quite clear. A definition often used expresses broadband as downstream capacity greater than ISDN $(2 \times 128 \mathrm{kbit} / \mathrm{s}+16 \mathrm{kbit} / \mathrm{s}=144 \mathrm{kbit} / \mathrm{s})$. Other alternatives used, are $384 \mathrm{kbit} / \mathrm{s}$ or $512 \mathrm{kbit} / \mathrm{s}$. The costs to cover the broadband residual market increase as a function of the defined minimum access capacity.

\subsection{Market evolution and penetration forecasts}

To evaluate broadband rollout strategies, broadband modelling and long-term broadband access forecasts have been developed. The broadband forecast modelling is based on work in the techno-economic project ECOSYS $[1,2]$.

\subsection{Broadband coverage}

The average broadband coverage in Western Europe was $91 \%$ at the end of 2004. Most countries had a broadband coverage of $90 \%$ or more, but some countries like Greece, Ireland and Norway had a significantly lower broadband deployment. Also in 2005 the broadband accesses have been deployed rather extensively. In Norway the broadband DSL coverage increased from $82,0 \%$ to $88,4 \%$ at the end of 2005 .

Figure 2 shows coverage of the Western European countries for DSL and Cable modems as of December 2004.

The rollout plans and the rollout possibilities for different broadband technologies are important factors for the future broadband coverage and for the broadband penetration forecasts.

\subsection{Relevant broadband technologies for the residual market}

Newly updated forecasts for the Western European broadband market based on the methodology showed in [1] have been developed. Figure 3 shows the market share forecasts of the most dominating technologies. The forecast modelling is based on Logistic models with four parameters.

The figure shows that DSL and cable modem are the dominating broadband technologies in Western Europe. Other technologies have relatively small market shares in the period 1999-2006. The most important technologies in this group are FWA and FTTB/FTTH. The fibre solutions are rather expensive to establish and are not candidates for the residual market for most of the countries in Western Europe. The HFC network is an enhancement of the traditional TV distribution network, which has been rolled out in urban and suburban areas. The HFC network will not be deployed in rural areas because of very high investment costs. Hence, HFC (cable modem) is not a candidate for the broadband residual market.

DSL is an important alternative for the broadband residual market. However, the technology has limitations. First of all, the copper loop length limits 


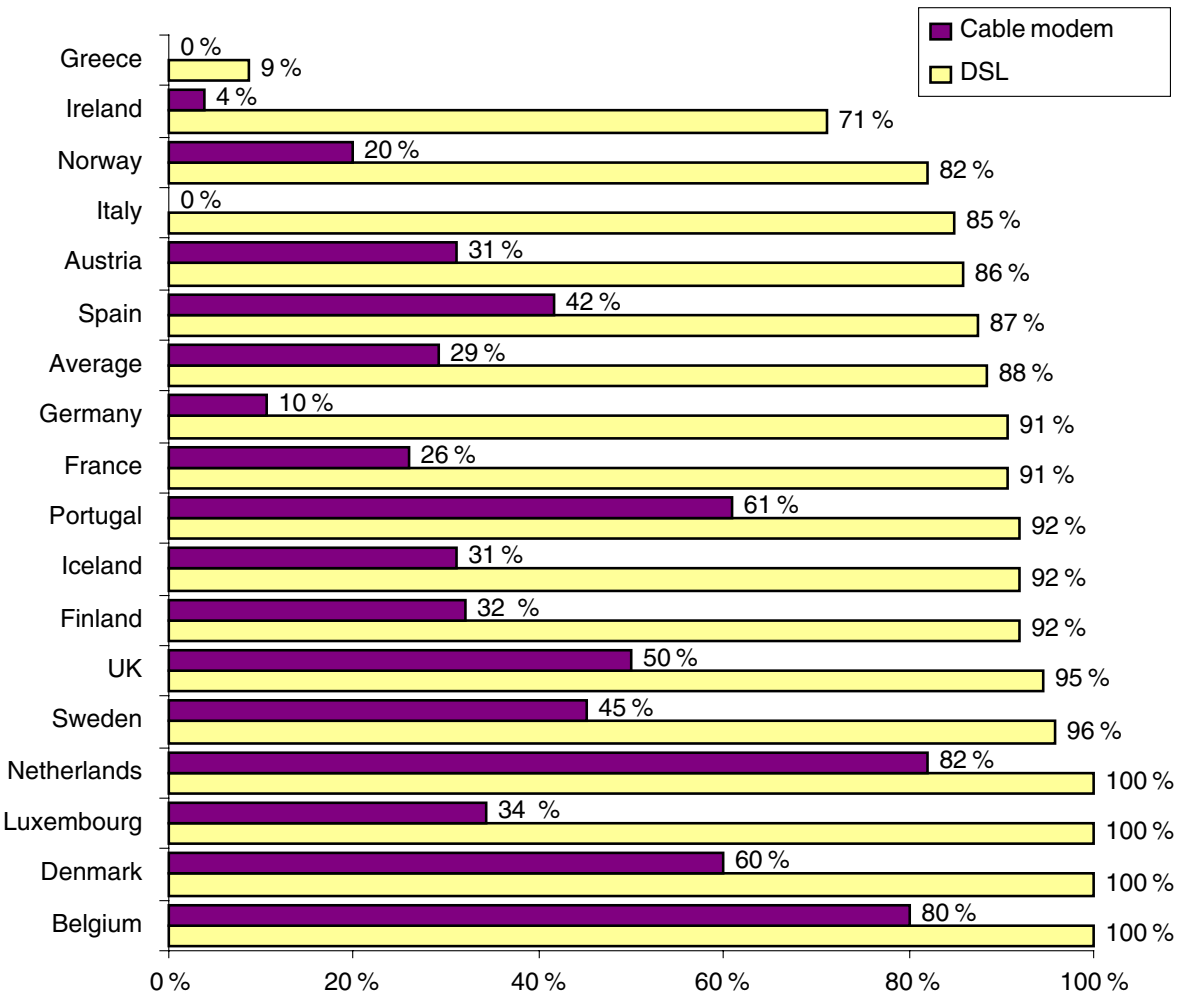

Fig. 2 Broadband deployments in Western Europe December 2004 [1]

the coverage possibilities. Secondly, it will not be profitable to cover too small areas with DSLAM installations because of too high investments per customer.

Other possibilities are especially WiFi, WiMAX and satellite. For some countries also the Digital Terrestrial Television network (DTT) could be a candidate. The network has limited capacity for individual communication and the network will probably be deployed too late.

\subsection{Broadband penetration forecasts for the residential market}

Newly updated forecasts for the Western European broadband market based on the methodology presented in [4], have been developed. Figure 4 shows the penetration forecasts.

The figure shows the broadband penetration forecasts per household for the residential Western European market. The mean value for the all countries in Western Europe is shown in the figure. There are of course great differences between the Western European countries. The Netherlands, Switzerland, Belgium and the five Nordic countries have a significantly higher penetration than the mean value for 2005, while especially Greece and Ireland have a very low broadband penetration [5]. 


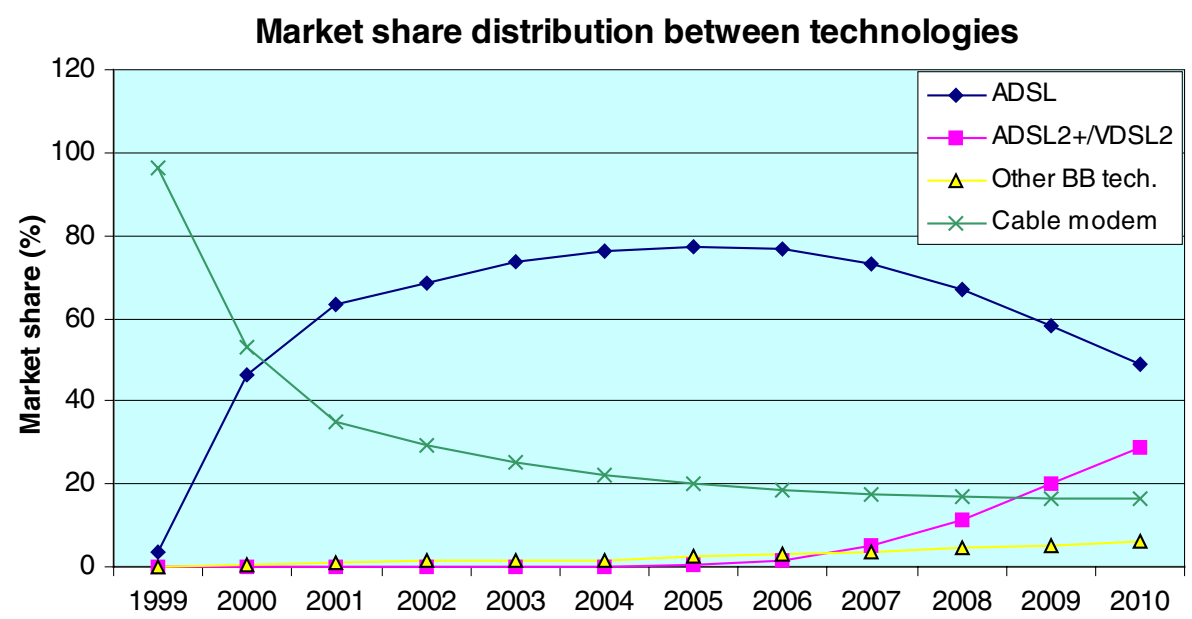

Fig. 3 Market share forecasts between ADSL, ADSL2+/VDSL, Cable modem and other technologies for the West European residential market

\subsection{Broadband forecasts for the business market}

The broadband forecasting model for Western Europe has not been easily developed because of lack of data. The most important statistics used is the Western European broadband survey conducted by Idate and supported by the European Commission Idate [6] Point topics [7] and broadband statistics from OECD [5].

A central element of the access forecasts is the long-term saturation level. The number of business units for Western Europe reported in [4] is a basis for the saturation level. A business unit is placed at an independent location

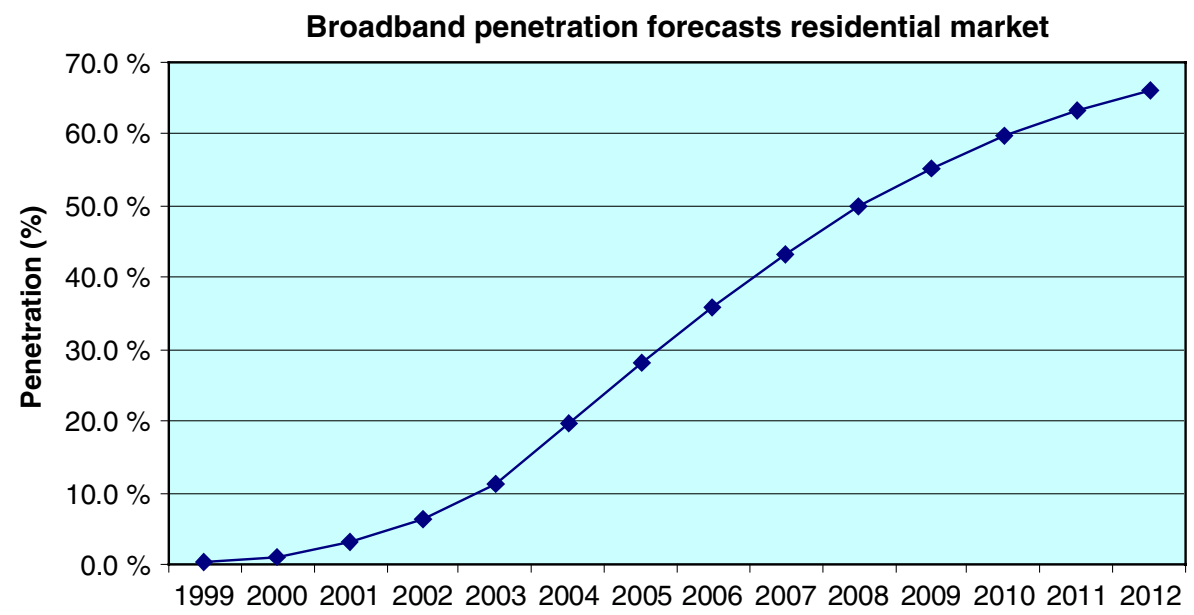

Fig. 4 Broadband penetration forecasts for the residential market, Western Europe 


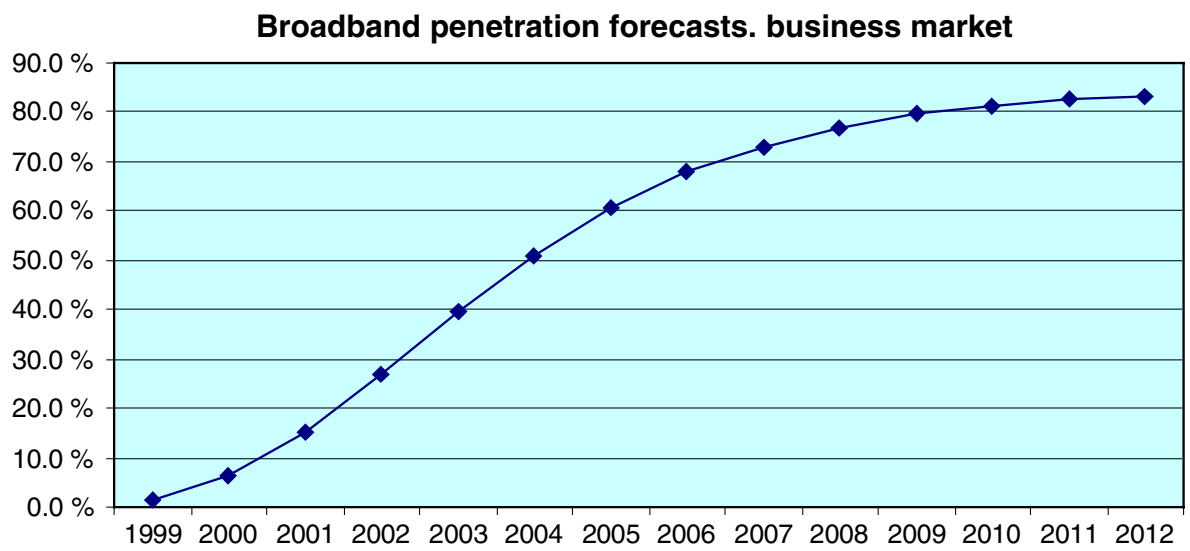

Fig. 5 Broadband penetration forecasts for business market, Western Europe

and a company consists of one or more business units. $62 \%$ of business units in Norway are units without employees and many of these units have been constructed to avoid taxes etc. [8]. It is assumed that only a limited number of the business units without employees are ordering broadband access. On the other hand, larger business units have a potential to order more than one broadband accesses. The number of accesses needed depends of number of employees and the traffic concentration, which is a function of the busy hour concentration factor and the packet switching concentration factor. It is assumed that not all employees are using the broadband access. The traffic concentration factor is assumed to be 1:20. The traffic concentration factor will of course depend on the evolution of higher capacity connections and the evolution of usage of high capacity applications.

The number of business units in Europe is found in [6]. Based on the traffic concentration factor and reduction of business units, which are expected not to order broadband access, the broadband access potential for the business market in Western Europe is estimated. Figure 5 shows the penetrations forecasts.

Statistics from [6] indicates that the volume of accesses in the business market in EoY 2004 was about 19\% of the total volume of broadband accesses. Because the broadband evolution in the business market is closer to saturation than the residential market, the market share ratio increases in favour of the residential market.

The adoption rate forecast used in the analysis takes into account the different evolutions of the two markets.

\subsection{Adoption rate forecasts}

The penetration forecasts are shown in Figs. 4 and 5. The coverage is shown in [4]. Based on the business and residential market potentials, the penetration forecasts and the coverage, the adoption rate forecasts are calculated. 
The adoption rate forecasts express the sum of business and residential accesses per potential subscriber. Potential subscribers in the area are defined as the sum of the households and relevant business units including possible additional business accesses (Business units with more than 20 employees will have more than one potential broadband access).

In the analysis different adoption rate forecasts are used to evaluate the broadband rollout options. Adoption rate forecasts with modest evolution are represented by countries in central Europe while adoption rate forecasts with more aggressive evolution are represented by the Nordic countries. The adoption rate forecasts are reduced because assumption of lower broadband demands in rural than in urban areas. Since information about lower demand in sparsely populated areas is not available, the reduction factor is set to $10 \%$ for the central European rollout case and $5 \%$ for the Nordic rollout case.

Many business case calculations are based on immediate rollout the first month of the year. The rollout presented here, assumes that the rollout is in the middle of the first year. This is also representative for an operator with a portfolio of rollout projects.

Experiences have shown that it takes time from the DSLAM is installed and the DSL is offered, to the customers have ordered DSL (to the adoption rate demand is reached). The model assumes that the demand gradually increases in a 4 months period until adoption rate is reached.

The adoption rate forecasts for rural areas are shown in Fig. 6 for Central European and the Nordic countries. The adoption rate forecasts are not corrected for entering the area in the middle of the year and the delay in the adoption.

Adoption rate forecasts for rural areas in Central Europe and Nordic countries

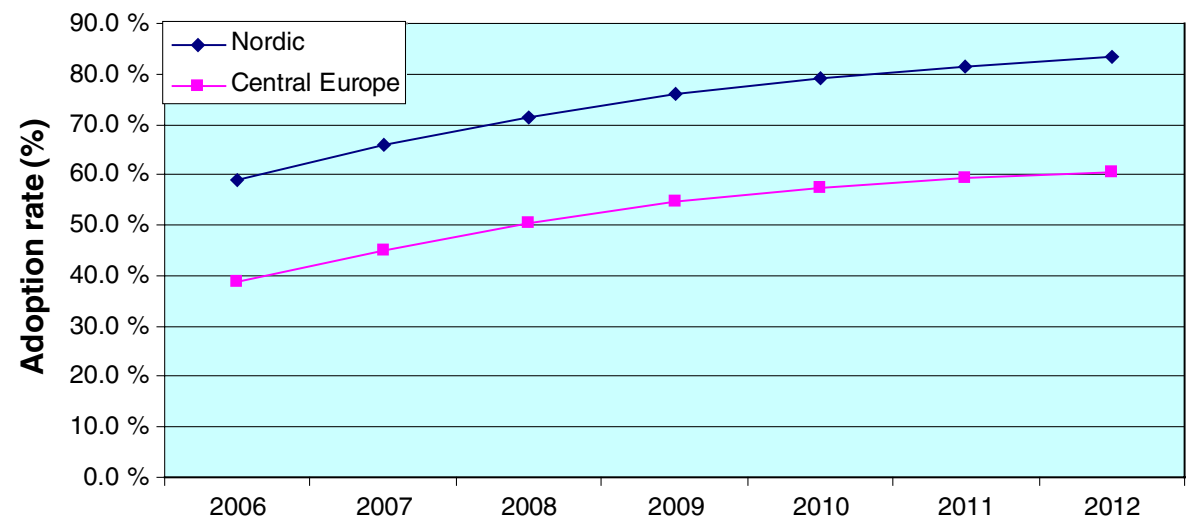

Fig. 6 Adoption rate forecasts, mixed residential business for rural areas in central Europe and Nordic countries 


\subsection{Business case model}

The model describes important characteristics of the access areas. Furthermore, copper loop length distribution, distributions of number of potential subscribers and distributions of market share between residential and business accesses are combined. The techno-economic calculations examine broadband rollout in the different access areas.

The most important factors are copper loop lengths and the number of subscribers in the area.

Areas analysed are assumed to have ADSL coverage of $95 \%$ and ADSL2+ coverage of $70 \%$.

The areas analysed are rural with $5 \%$ potential business accesses and $95 \%$ potential residential accesses. Potential subscribers are defined as available subscribers in the long-term.

The reference level for monthly ARPU is set to 40 Euro per month with a $5 \%$ reduction the first year. The argumentation for the stable ARPU level is minimal competition and the possibility to offer higher capacities and ADSL2+. The business market contributes marginally to higher ARPU because of the relatively small proportion of business accesses. The reference level for the connection fee is 30 Euro.

The CAPEX cost elements as follows:

- ADSL2+ line cards

- Mini DSLAM

- DSLAM interface

- DSLAM installation and power

- DSLAM internal cabling

- Backhole costs to DSLAM

The cost predictions are found by using the learning curves [8].

The OPEX costs is segmented in the following main segments

- IP cost per subscriber

- Network operations cost per subscriber

- Support and billing costs per subscriber

- Sales and marketing costs per subscriber

The discount rate is $10 \%$ and the riskfree rate of return is $5 \%$. The investment horizon is 2006-2015. The study period could, alternatively have been shorter i.e. 2006-2011 with a terminal value. Because of a monopoly situation for the operator with minimal risks, a fairly long study period is acceptable.

\subsection{Techno-economic calculations}

A techno-economic tool is used to calculate the economical value of broadband rollouts. The tool and the techno-economic methodology have been 
developed by the European programs RACE, ACTS, IST and EUREKA/ CELTIC through the projects RACE 2087/TITAN, AC 226/OPTIMUM, AC364/TERA, IST-2000-25172 TONIC and ECOSYS. The techno-economic methodology and the tool calculate the overall financial budget of any access architecture. The tool handles the discount system costs, operations, maintenance costs, life cycle costs, net present value (NPV) and internal rate of return (IRR). The tool is well suited to combine low level, detailed network parameters of significant strategic relevance with high level, overall strategic parameters for performing evaluation of various network architectures. More detailed descriptions of techno-economic modelling and the tool are found in [9].

To evaluate broadband rollout strategies for the residual market, technoeconomic analysis uses the generic access area models, broadband adoption rate forecasts and predictions of other important factors like tariffs, component costs, operation and management costs etc

\subsection{Roll out analysis}

The DSL rollout analysis handles two main cases:

- A central European case

- A Nordic case

\subsubsection{Central European case}

Net present value (NPV) for DSL broadband rollout has been calculated as a function of the number potential subscribers in the area. The calculations have been performed for to examine the sensitivity of NPV, when the adoption rate forecasts are changing. Three different alternatives for the adoption rate forecasts are used:

- Pessimistic adoption rate forecasts

- Default adoption rate forecasts

- Optimistic adoption rate forecasts

The default adoption rate forecasts are shown in Fig. 4. The pessimistic adoption rate forecasts ends $10 \%$ lower than the default adoption rate forecasts in 2015, while the optimistic adoption rate forecasts end $10 \%$ higher in 2015. The default adoption rate forecasts are close to, but not identical to the Western European mean.

Figure 7 shows the results. The results presuppose a monopoly area.

The figure shows that the NPV is positive for the default adoption rate case where there are 50 or more potential subscribers in the area. With a pessimistic adoption rate the critical number of potential subscribers in the area is 55 .

Suppose a second operator enters the same areas as operator no 1 , but is one year delayed. Then the new operator will loose the initial demand and is 
NPV of DSL rollout as a function of potential

subscribers. Monopoly.

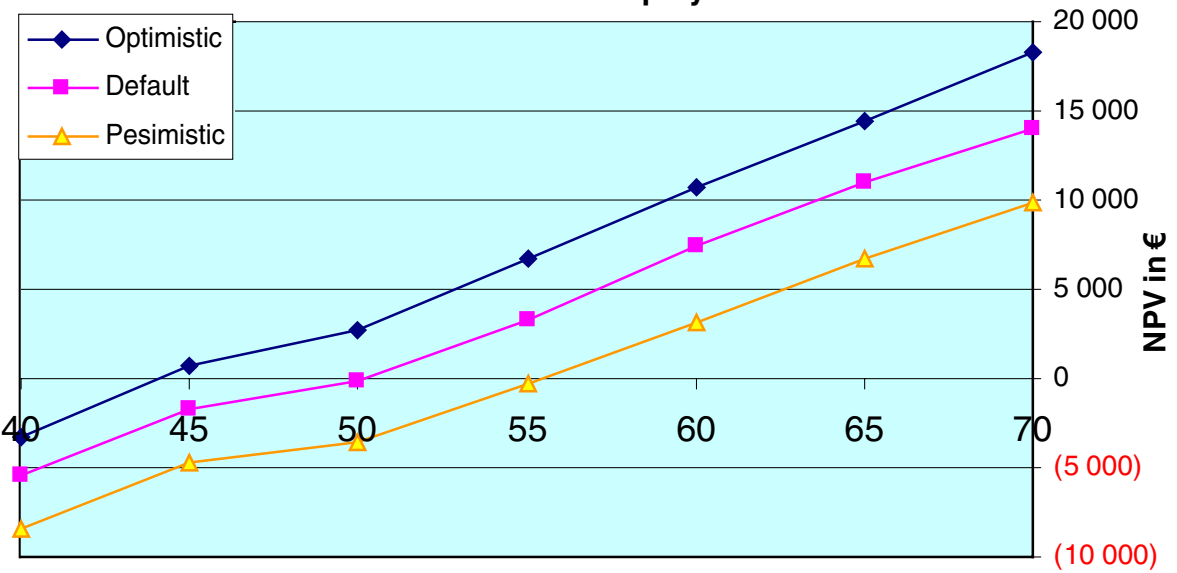

Potential subscribers

Fig. 7 NPV of DSL rollout as a function of potential subscribers and different adoption rates. Monopoly. Central European case

only able to fight to get parts of the yearly growth. It is assumed that operator no. 2 takes $20 \%$ of the growth the first year and $50 \%$ the next years.

Figure 8 shows the NPV for operator no 1 in the case when a new operator enters the area one year delayed.

Because of the new competitor, the critical size for the DSL rollout has changed from 50 to 58. The relevant question is what type of analysis the new operator has done, since the operator will never get a positive business case

NPV of DSL rollout as a function of potential

subscribers. Competitor one year delayed

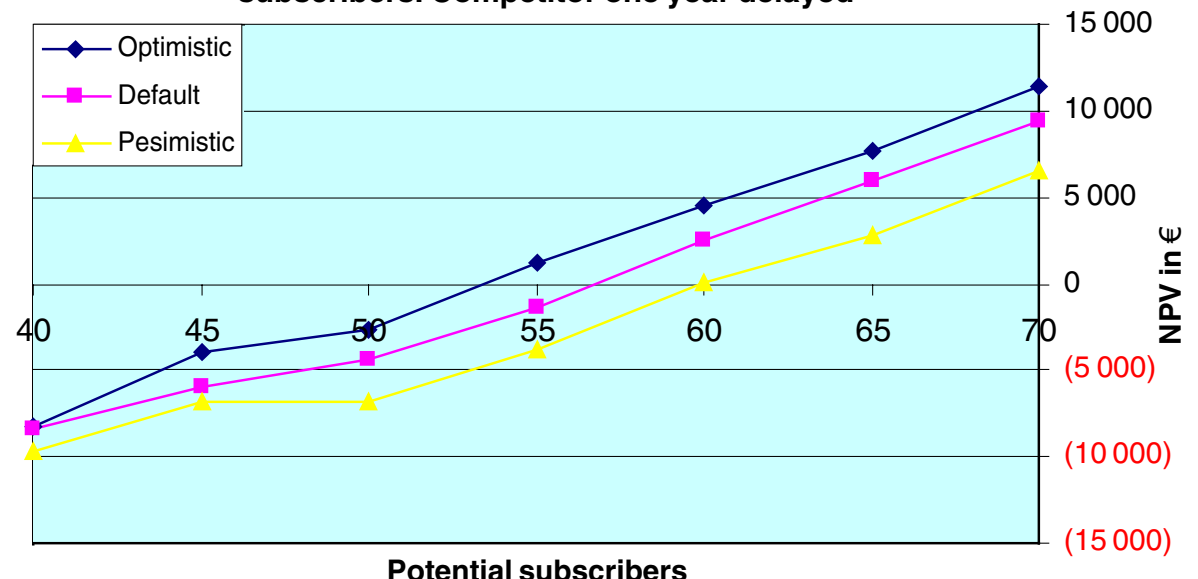

Fig. 8 NPV of DSL rollout as a function of potential subscribers and different adoption rates. Competitor one year delayed. Central European case 
simply because the operator was too late and had no possibility to utilise the first mover's advantage!

However, the conclusion is that the operator no. 1 has a fairly good business case, independent of entrance of a competitor. The explanation is that the first mover's advantage is utilised before new operators are entering the area.

Figure 9 shows how the NPV for DSL rollout in an area with 40 potential subscribers is changing when the value of the main critical variables deviates from their default value.

The vertical line in the figure shows the default values of the critical variables. The NPV is about $-5.000 €$. A positive NPV require that the monthly ARPU level has to increase from $40 €$ to $45 €$. Another option is to find dense areas concentrations where the distance between the exchange and mini DSLAM is not too long, such that the backhaul costs are less than $20.000 €$.

Figure 9 indicates clearly that the ARPU, backhaul costs, broadband adoption and to some extent support/billing are the variables which have the strongest influence on the ARPU.

\section{NPV [k€] \\ (Potential lines: 40)}

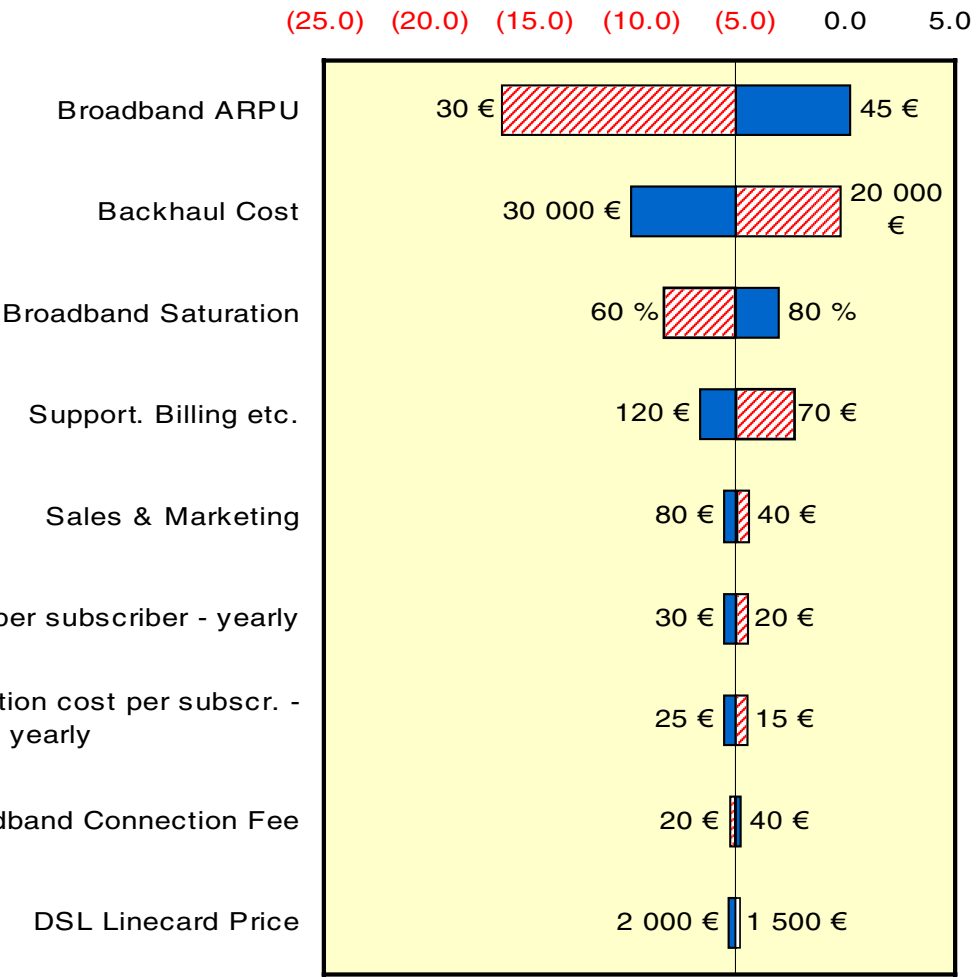

Fig. 9 Sensitivity analysis. NPV of broadband rollout in an area with 40 potential subscribers. Monopoly area. Central European case 


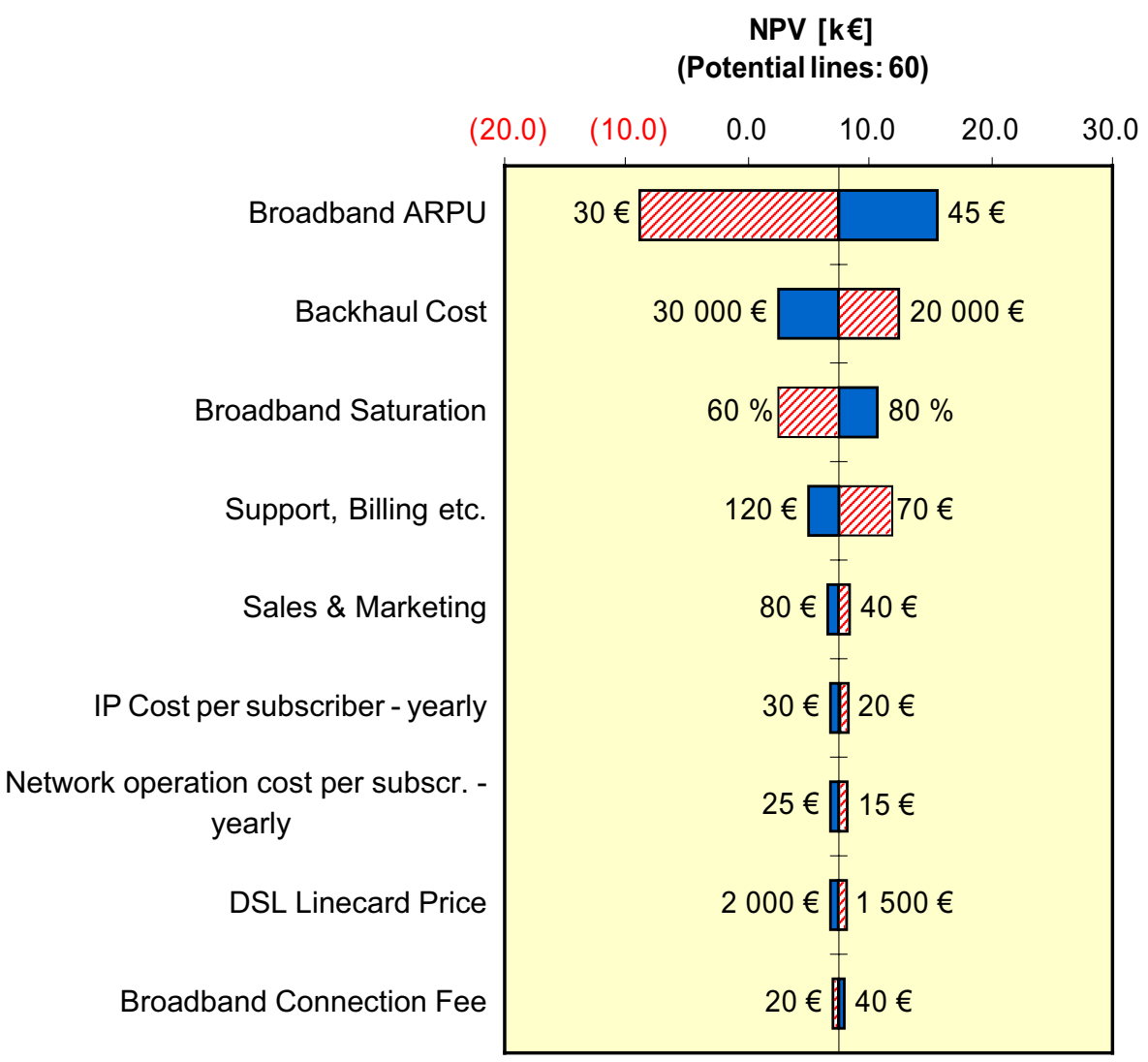

Fig. 10 Sensitivity analysis. NPV of broadband rollout in an area with 60 potential subscribers. Monopoly area. Central European case

Figure 10 shows the same analysis for an area with 60 potential subscribers. When the DSL rollout area has 60 potential accesses, the NPV is about $8.000 €$. Only a very low ARPU may squeeze the NPV below 0 . No other variables are significant in this respect.

\subsubsection{Nordic case}

In some Western European countries the broadband penetration is much higher than the mean West European penetration. Higher penetration will of course improve the rollout business case. The adoption rate forecasts for mixed business residential rural areas are shown in Fig. 6 . The adoption rate forecasts for central Europe starts with 35\% EoY 2005, while the Nordic adoption rate forecasts starts with 54\% EoY 2005.

The Nordic case is analysed with and without competition. The analysis performed is based on the incumbent point of view. In case of competition, 
it is assumed that operator no 2 enters one year later than the first one and takes $20 \%$ of the growth the first year and $50 \%$ of the growth the next years.

Figure 11 shows the NPV as a function of the number of potential subscribers in the area.

When the area is a monopoly area, the number of potential subscribers must be 34 or more to reach a positive NPV. If another competitor enters the area one year delayed, the critical size of the areas is 38 potential subscribers. The adoption rate for the Nordic case, see Fig. 6, shows that the adoption rate is increasing slowly from 2007. The yearly growth is not very large in absolute terms. Hence, the loss for operator no 1 by sharing $50 \%$ of the yearly growth with operator no. 2 is not a very great loss, compared to the initial gain catching $60 \%$ of the potential subscribers during the first year.

The analysis of the Nordic broadband rollout case shows clearly the first mover's advantage. In situations where the adoption rate is very high, it is crucial to roll out broadband before other competitors are entering the areas.

Figure 12 shows the results of a sensitivity analysis of the Nordic case with area size of 40 potential subscribers.

The figure shows that only large changes in the ARPU will reject rollout when there are 40 or more potential subscribers in the area.

Figure 13 shows the sensitivities in NPV for operator no. 1 when a new operator enters the area one year delayed.

When there is competition in the area, rollout in areas with 40 potential subscribers give a positive net present value. However, changes in the critical variables may change the NPV value to be negative.

\section{NPV for operator no. 1 as a function of potential subscribers in area with monopolly and area with competition}

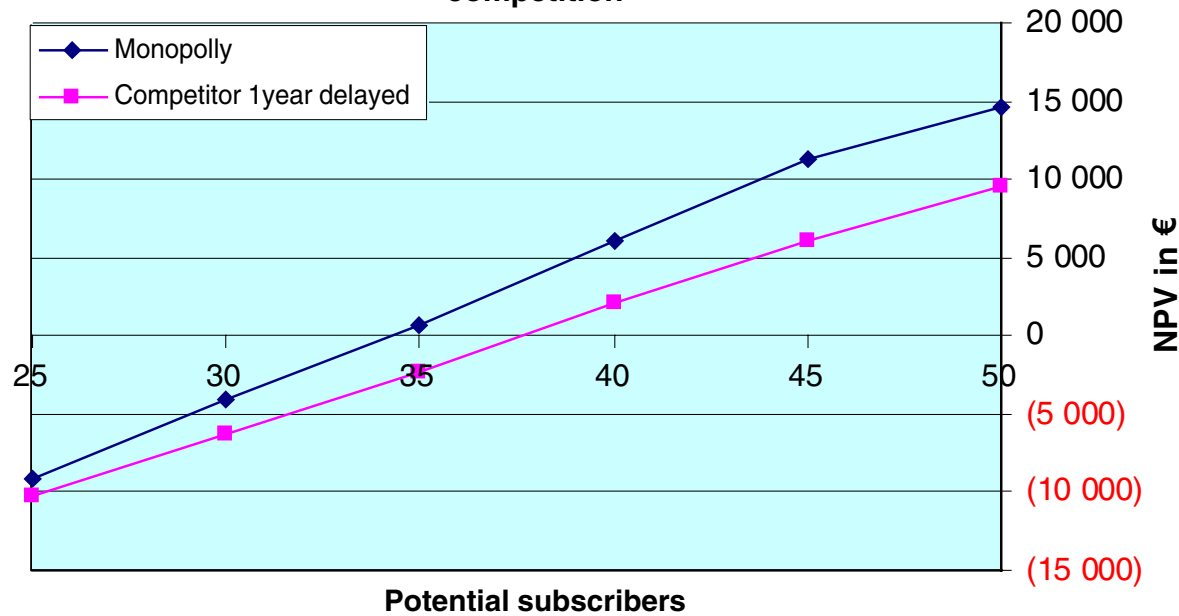

Fig. 11 NPV as a function of potential subscribers in the area with and without competition. Nordic case 


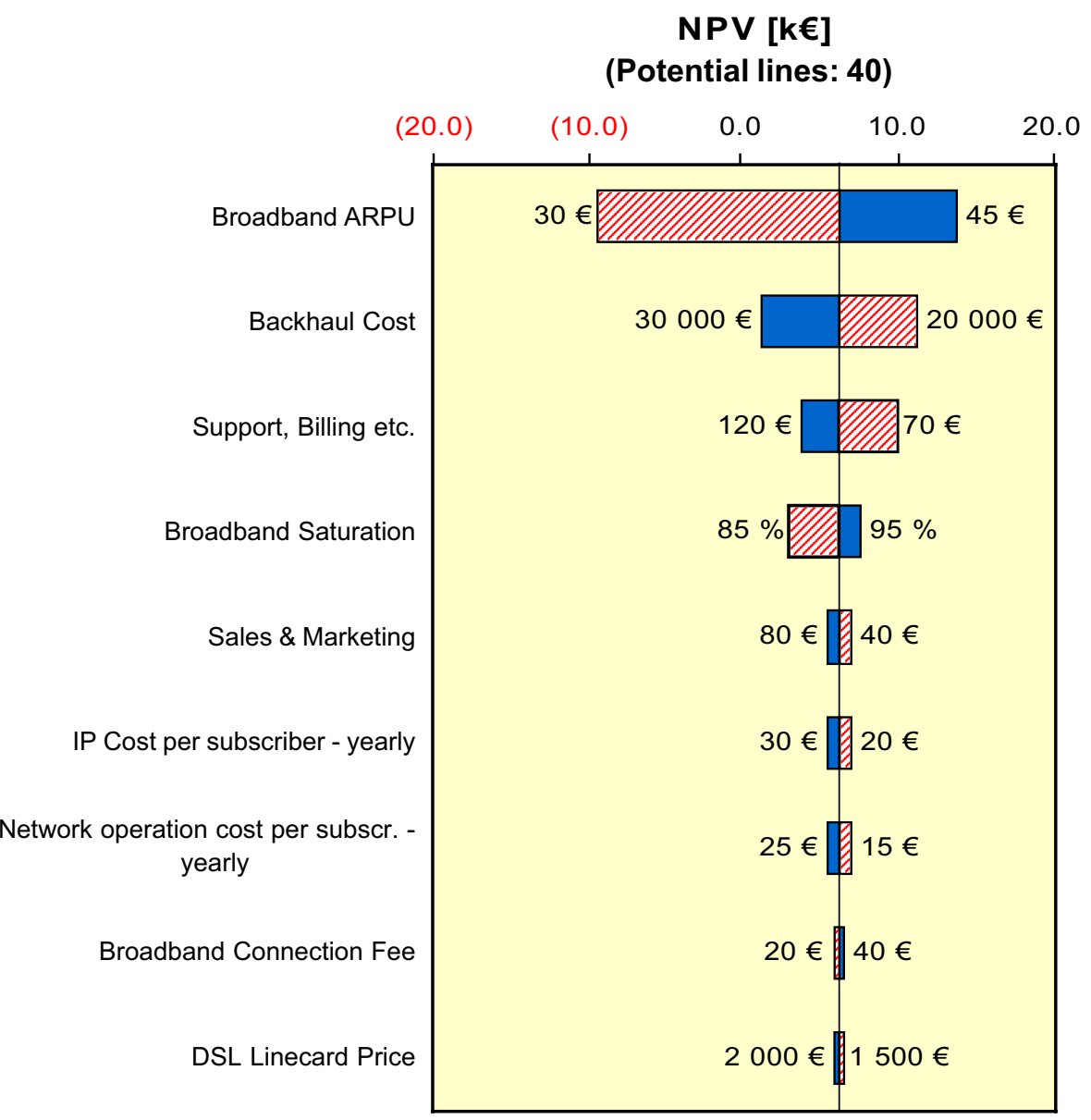

Fig. 12 Sensitivity analysis. NPV of broadband rollout in an area with 40 potential subscribers. Monopoly area. Nordic case

\section{Rollout strategies and conclusions}

The adoption rate forecasts distinguish between the operator who enter a local area as the first one and operators who enters later. The first operator catches all initial demand, which has been aggregated through many years, while the other operators have to fight to win parts of the growth in the following years.

Stordahl et al. [2] shows how adoption rate forecasts are used to roll out ADSL2+/VDSL and presents ADSL2+/VDSL rollout strategy based on a set of analyzed scenarios. The optimal rollout strategy is to start the roll out in large exchange areas, followed by proactive rollouts compared with the other competitors. 


\section{N P V [ k€] \\ (Potential lines: 40)}

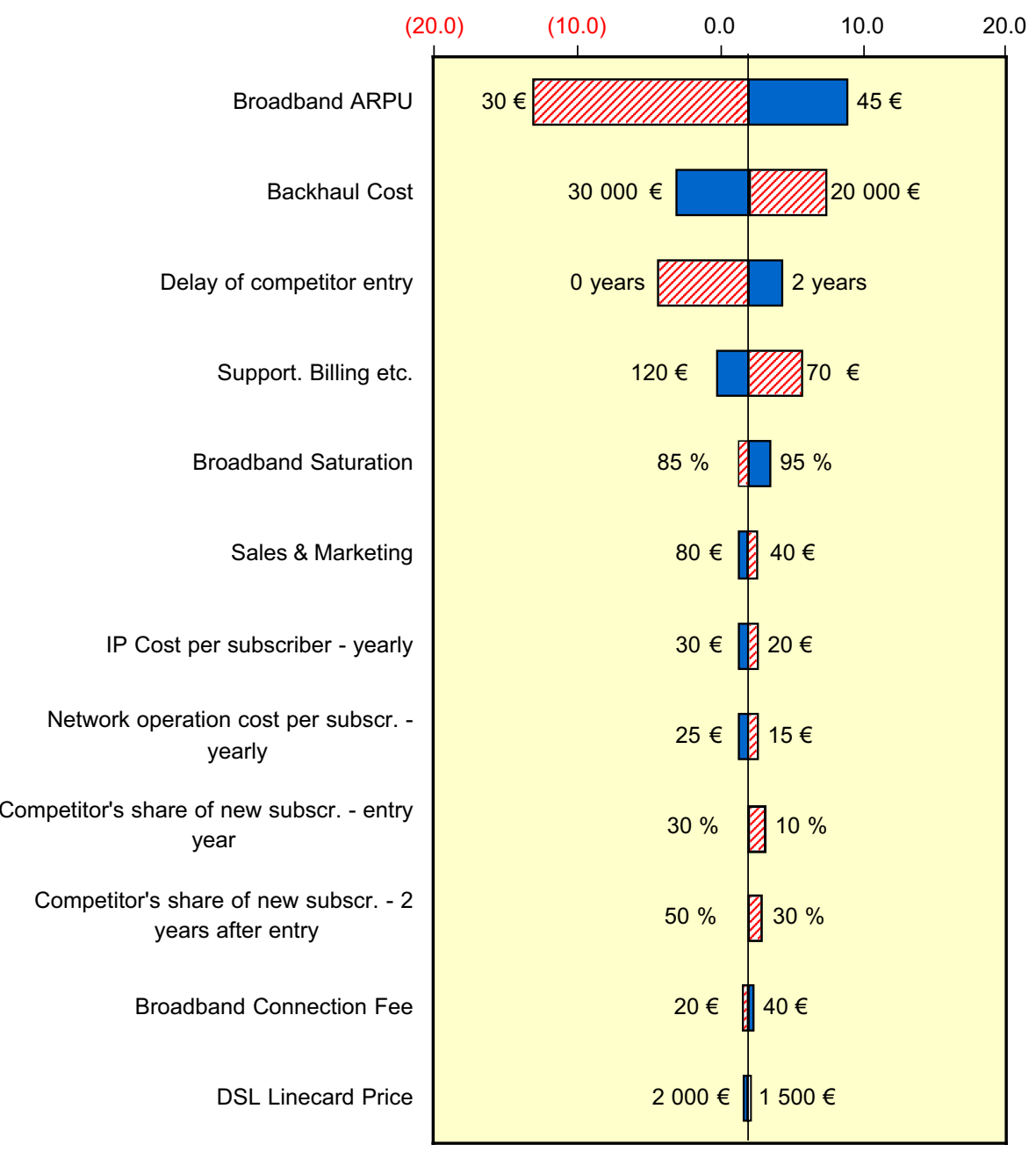

Fig. 13 Sensitivity analysis. NPV of broadband rollout in an area with 40 potential subscribers. Competition area. Nordic case

The analysis shows that the most critical variables in the rollout analysis are:

- The size of the area

- ARPU

- Backhaul costs

- Adoption rate forecasts

For the central European monopoly case, the operator reaches positive NPV when number of the potential subscribers in the area is about 50. In case 
a new operator enters the area one year delayed, the critical value for operator no. 1 is an area size of 58 potential accesses.

The Nordic case has much higher adoption rate than the central European case. The operator who rolls out broadband, needs only to have 34 potential subscribers to get a positive NPV. In case of competition (competitor one year delayed) the critical number of potential subscribers is 38 . The very small difference between the critical values with and without competition is caused by the high adoption rate when the rollout starts.

The ARPU is the most uncertain variable; hence it has the strongest influence on NPV. But the ARPU is also the key variable. Since the area is a monopoly, the operator may claim higher ARPU in these sparsely populated areas, arguing that the costs are higher for the broadband rollout. Another option is supplementary financing from the government (The Norwegian case) or from the municipalities. If so, rollout of DSL may occur in even smaller areas.

Only some figures have been presented to show the critical area size for DSL rollouts. There are many combinations of the values of the critical variables, which have not been presented. However, there will only be minor changes in the results if the variables do not deviate from the intervals shown in the figures.

The analysis of the Nordic broadband rollout case shows very clearly the first movers advantage. In situations where the adoption rate is very high and the areas are too large, it is crucial to roll out broadband before other competitors enters the area. If not the whole area may be lost.

Open Access This article is distributed under the terms of the Creative Commons Attribution Noncommercial License which permits any noncommercial use, distribution, and reproduction in any medium, provided the original author(s) and source are credited.

\section{References}

1. Stordahl, K. (2004). Long-term broadband technology forecasting. Telektronikk, 100(4), 13-31.

2. Stordahl, K., Elnegaard, N. K., Olsen B. T., \& Lähteenoja, M. (2004). Competition in the local loop-how to minimize the market risks. In Proc. $X V$ international symposium on services in the local access-ISSLS 2004 (pp. 21-24). Edinburgh, Scotland (March).

3. OVUM (2005). EuroView, 14. November.

4. Idate (2005). Broadband access development in Europe. Final results European Idate (2004) Broadband demand data, June 2003-December 2004 (Unpublished).

5. OECD (2005). Broadband Statistics OECD, 20. October 2005. http://www.oecd.org/document/ 16/0,2340,en_2649_34225_35526608_1_1_1_1,00.html.

6. Idate (2004). Broadband demand data, June 2003-December 2004 (Unpublished).

7. Point topic (2005). Point topic world broadband statistics (Quarterly), 2003-2005 8. SSB (2006) Statistics Norway. http://www.ssb.no/bedrifter/tab-2006-01-20-01.html.

8. Olsen, B. T., \& Stordahl, K. (2004). Models for forecasting cost evolution of components and technologies. Telektronikk, 100(4), 138-148.

9. Ims, L. A. (1998). Introduction strategies and techno-economic evaluations. Boca Raton, Florida: Chapman \& Hall, ISBN 0412828200. 